\title{
STUDY OF CLINICAL AND LABORATORY PROFILE IN PATIENTS OF FEVER WITH THROMBOCYTOPENIA AND ITS OUTCOME DURING HOSPITAL STAY- A STUDY AT RIMS, A TERTIARY CARE HOSPITAL AT ONGOLE, PRAKASAM DISTRICT OF ANDHRA PRADESH
}

\author{
Gudi Srinivas ${ }^{1}$, Yarram Rajeswara Rao ${ }^{2}$
}

${ }^{1}$ Associate Professor, Department of General Medicine, Rajiv Gandhi Institute of Medical Sciences, Ongole, Andhra Pradesh, India. ${ }^{2}$ Assistant Professor, Department of General Medicine, Rajiv Gandhi Institute of Medical Sciences, Ongole, Andhra Pradesh, India.

\begin{tabular}{l}
\hline ABSTRACT \\
FACKGROUND \\
it is not often looked for and the required investigations are not generally asked for.
\end{tabular}

\section{MATERIALS AND METHODS}

A hospital-based descriptive study conducted at Rajiv Gandhi Institute of Medical Sciences (RIMS), Ongole on 115 patients with fever associated with thrombocytopenia. Study duration was for one and a half years from January 2016 to June 2017. Data was collected using a semi-structured questionnaire, either by direct interview with patients or patient's relatives and by clinical examination and from relevant investigations. Patients were regularly monitored and depending on aetiological basis appropriate treatment was given.

\section{RESULTS}

Out of the 115 patients, dengue was the most common diagnosis found in the present study with 60\% (n= 69) followed by unknown viral fevers (15.6\%), then malaria (8.8\%) and sepsis (6.1\%). 5 cases were HIV positive, 3 cases had viral hepatitis and 3 enteric fever. Out of the total 69 dengue cases, 20 cases (28.9\%) had platelet count in range of 40,001-60,000. 17 cases had in range of 20,001 - 40,000 and 15 dengue cases had severe thrombocytopenia $(<20,000) .110$ cases $(95.6 \%)$ showed good recovery, 2 patients expired, and 3 patients left against medical advice.

\section{CONCLUSION}

Febrile illness patients should be investigated for low platelet count whether they have bleeding manifestations or not. A routine CBC (complete blood count) investigation in all febrile illness cases will help to find its association with thrombocytopenia.

\section{KEY WORDS}

Fever, Thrombocytopenia, Clinical and Laboratory Profile, Outcome.

HOW TO CITE THIS ARTICLE: Srinivas G, Rao YR. Study of clinical and laboratory profile in patients of fever with thrombocytopenia and its outcome during hospital stay- a study at RIMS, a tertiary care hospital at Ongole, Prakasam district of Andhra Pradesh. J. Evolution Med. Dent. Sci. 2018;7(27):3092-3095, DOI: 10.14260/jemds/2018/694

\section{BACKGROUND}

Fever is a common manifestation caused by various diseases. It is an elevation of body temperature above normal circadian variation as a result of the change in the thermoregulatory centre, located in the hypothalamus.

Normal body temperature displays a diurnal pattern with lower values in the early morning hours and higher values in the afternoon. Normal ranges are between $35.8^{\circ} \mathrm{C}\left(96.5^{\circ} \mathrm{F}\right)$ and $37.2^{\circ} \mathrm{C}\left(99^{\circ} \mathrm{F}\right)$. Fever is superimposed on this pattern and thus temperatures are usually greatest in the afternoon and evening. Fever implies an elevated core body temperature of more than $38.0^{\circ} \mathrm{C}$ and is a response to cytokines and acute phase proteins.

'Financial or Other Competing Interest': None.

Submission 06-06-2018, Peer Review 18-06-2018,

Acceptance 20-06-2018, Published 02-07-2018.

Corresponding Author:

Dr. Yarram Rajeswara Rao,

House No. 37-1-383 (112),

Indira Colony, Opp. Dr. Ambedkar Bhavan,

Ongole, Prakasam-523001,

Andhra Pradesh, India.

E-mail:yarram.rajeswararao@gmail.com

DOI: $10.14260 /$ jemds $/ 2018 / 694$
Thrombocytopenia may arise from either decreased or abnormal production such as infections, folate and vitamin B12 deficiency, leukaemia or increased destruction such as idiopathic thrombocytopenic purpura (ITP), thrombotic thrombocytopenic purpura (TTP), haemolytic uraemic syndrome (HUS), disseminated intravascular coagulation (DIC) and few other conditions.[1,2]

Fever with thrombocytopenia may manifest in infective conditions such as dengue, malaria especially during monsoon and peri-monsoon period. Many other infective conditions by various bacteria, viruses and protozoa may also present with fever with thrombocytopenia. These infections cause decrease in platelet count both due to effects on platelet production and survival.[3,4]

Management strategy for fever with thrombocytopenia includes antipyretics for control of fever, rehydration with intravenous fluids, avoiding aspirin/ anticoagulants, platelet transfusion if the platelet count is $<20,000$ or clinical bleeding and specific therapy once the diagnosis is established.[5,6]

It is well known fact in medicine that one can diagnose a disease only when one is aware of the disease and looks for it. Thrombocytopenia is often missed, because it is not often looked for and the required investigations are not generally asked for. Now with increasing awareness of the association 
of thrombocytopenia with various illnesses, especially with febrile illness this entity is now viewed with due regards.

The objectives of the present study were to identify the aetiological cause of fever with thrombocytopenia, to evaluate clinical profile and to assess the clinical outcome/complications associated at RIMS, a tertiary care hospital at Ongole, Prakasam District of Andhra Pradesh.

\section{MATERIALS AND METHODS}

A hospital-based descriptive study conducted at Rajiv Gandhi Institute of Medical Sciences (RIMS), Ongole on patients with fever associated with thrombocytopenia. Study duration was for one and a half years from January 2016 to June 2017. A total of 115 patients with fever associated with thrombocytopenia were selected for the study.

\section{Exclusion Criteria}

Leukaemias and Haematopoietic disorders inherited caused of thrombocytopenia, patient on drugs causing thrombocytopenia, cirrhosis of liver, autoimmune causes, HIV infection, underwent chemotherapy/ radiotherapy.

\section{Study Procedure}

An informed consent was taken. Data was collected using a semi-structured questionnaire, either by direct interview with patients or patient's relatives and by clinical examination and from relevant investigations.

Detailed case history was taken especially with regards to onset, duration and type of fever. Any associated symptoms such as headache, myalgia, joint pains, loose stools, pain abdomen, breathlessness and bleeding manifestations (e.g. petechiae, gum bleeding, melena, bleeding PV) during admission.

\section{Investigations}

a. Complete haemogram.

b. Liver function test.

c. Renal function test.

d. Peripheral smear for malaria.

e. Widal test

f. IgM ELISA dengue.

g. Blood culture.

h. Radiological investigations- Chest x-ray, USG abdomen and other relevant investigations were done to achieve the diagnosis.

Patients were regularly monitored and depending on aetiological basis appropriate treatment was given. The outcomes (duration of hospital stay, complications if any) were analysed and in case of patient's death cause of death is noted.

Statistical Analysis: The data was collected, coded and entered into Microsoft Excel 2010. The whole data was rechecked and analysed using Epi Info version 7. Numerical variables were presented as Mean and Standard deviation (SD). Categorical variables were expressed as frequencies and percentages.

\section{RESULTS}

Present study included 115 patients who were admitted with fever associated with thrombocytopenia in Rajiv Gandhi Institute of Medical Sciences (RIMS), Ongole from January 2015 to June 2017.
The mean age of the study population was $46.26 \pm 11.5$ years with majority (34.8\%) subjects belonging to $41-50$ years' age group followed by 31 - 40 years' age group (21.7\%). The proportion of males and females was $56.5 \%$ $(n=65)$ and $43.5 \%(n=50)$ respectively.

\section{Clinical Presentation}

Apart from fever which was present in $100 \%$ of the patients, other symptoms included headache (74.8\%), myalgia (66.9\%) were the most common symptoms followed by pain abdomen (40.8\%), vomiting (39.1\%) and loose stools (30.4\%).

Petechiae (21.7\%), jaundice $(19.1 \%)$ and pallor $(13 \%)$ were major signs in the present study.

Out of the 115 patients, dengue was the most common diagnosis found in the present study with $60 \%(n=69)$ followed by unknown viral fevers $(15.6 \%)$, then malaria (8.8\%), sepsis (6.1\%), HIV (4.3\%), viral hepatitis and enteric fever $2.6 \%$ each respectively.

\begin{tabular}{|c|c|c|}
\hline Diagnosis & Number & Percentage \\
\hline Dengue & 69 & $60 \%$ \\
\hline Unknown viral fevers & 18 & $15.6 \%$ \\
\hline Malaria & 10 & $8.8 \%$ \\
\hline Sepsis & 07 & $6.1 \%$ \\
\hline HIV & 05 & $4.3 \%$ \\
\hline Viral Hepatitis & 03 & $2.6 \%$ \\
\hline Enteric fever & 03 & $2.6 \%$ \\
\hline \multicolumn{2}{|c|}{ Table 1. Aetiological Profile of the Study Population } \\
\hline
\end{tabular}

\begin{tabular}{|c|c|c|c|c|c|c|}
\hline 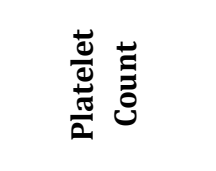 & 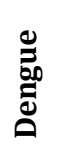 & 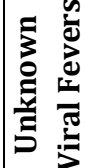 & $\frac{\sqrt[\pi]{3}}{\sum}$ & $\frac{n}{\tilde{n}}$ & & $\underset{0}{\pi}$ \\
\hline$<20000$ & 15 & 2 & 0 & 0 & 0 & $17(14.8 \%)$ \\
\hline $20001-40000$ & 17 & 2 & 0 & 4 & 0 & $23(20 \%)$ \\
\hline $40001-60000$ & 20 & 4 & 1 & 1 & 0 & $26(22.6 \%)$ \\
\hline $60001-80000$ & 13 & 9 & 8 & 1 & 3 & $34(29.6 \%)$ \\
\hline $80001-100000$ & 4 & 1 & 1 & 1 & 8 & $15(13 \%)$ \\
\hline Total & 69 & 18 & 10 & 07 & 11 & 115 \\
\hline
\end{tabular}

*Others include cases of HIV, viral hepatitis and enteric fever.

More than one-fourth (29.6\%) had platelet counts ranging from $60,001-80,000 / \mathrm{mm}^{3}$, about one-fourth $(22.6 \%)$ in a range of $40,001-60,000 / \mathrm{mm}^{3} .23$ patients had between 20,001 - 40,000 platelets and 15 had 80,001 $1,00,000$ platelets. $14.8 \%(n=17)$ patients had platelet count less than $20,000 / \mathrm{mm}^{3}$

Platelet count varied according to different aetiologies. Out of the total 69 dengue cases, 20 cases (28.9\%) had platelet count in the range of 40,001-60,000.17 cases had in range of 20,001 - 40,000 and 15 dengue cases had severe thrombocytopenia $(<20,000)$. Out of the 18 cases of unknown viral fevers, 2 cases each had platelet count in the range of 20,001 - 40,000 and $<20,000$ respectively and 9 cases had $60,001-80,000$. Out of the 10 cases of malaria, $80 \%$ had platelets in range of $60,001-80,000$. Among 7 cases of sepsis, 4 cases had in range of 20,001 - 40,000. 


\section{Outcome}

Out of 115 patients 110 cases (95.6\%) showed good recovery, 2 patients expired, and 3 patients left against medical advice.

Out of 2 cases of mortality, 1 died due to dengue shock syndrome and 1 due to complicated malaria.

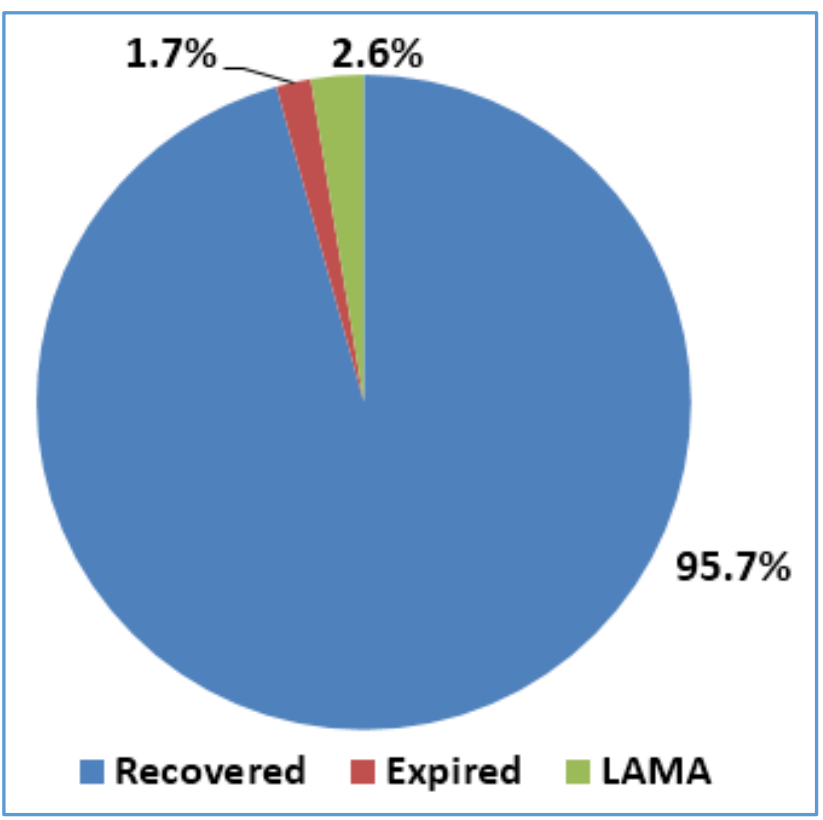

Figure 1. Outcome of the Study

\section{Platelet Transfusion}

Out of 115 patients 11 cases underwent platelet transfusion, of which 6 were transfused because of bleeding manifestations, whereas 5 underwent prophylactic transfusion due to low platelet levels.

\section{DISCUSSION}

The present hospital-based descriptive study on clinical and laboratory profile in patients of fever with thrombocytopenia and its outcome was done among 115 patients in the study period.

With regards to age and sex wise distribution of the cases, present study found a slight male preponderance of the cases (56.5\%) and one-third (34.8\%) subjects belonged to $41-50$ years' age group.

Sex distribution findings were in concurrence with M. P. Gondhali et al (2016),[7] where $56 \%$ and $44 \%$ of the cases were males and females respectively. Another study by Sujata S. Kumbhar et al (2017) ${ }^{[8]}$ also found similar findings where fever with thrombocytopenia was more common among males (59\%).

In contrast to study findings, age distribution by other studies had different findings. Raghunandan Meena and Naresh Kumar Meena (2016)[9] observed that $62 \%$ of cases were in 10 - 20 years' age group. Another study by Nikalje Anand et al (2016) ${ }^{[10]}$ found that highest number of cases was seen in the age group of 18 - 40 years $(75 \%)$ followed by 40 60 years $(16 \%)$ and then above 60 years were $9 \%$.

Aetiological profile: The causes of fever with thrombocytopenia may present as occult presentations than a rare disease. The diagnosis of which is one of the most challenging aspects.
In the present study, infections formed the major aspects for fever with thrombocytopenia. Among the infections, Dengue formed the most common cause with about twothirds of the study populations affected by it. Next common cause was found to be malaria then sepsis, HIV, viral hepatitis and enteric fever.

These findings were in accordance with M. P. Gondhali et al (2016),[7] where among the 100 cases of fever with thrombocytopenia all of them had a definite diagnosis with dengue fever being in more than half the cases. Septicaemia was the second common cause followed by malaria. Other conditions detected were HIV, viral hepatitis and typhoid.

In contrast to study findings in Sujata S. Kumbhar et al (2017)[8] study, most common cause of fever with thrombocytopenia was found to be malaria (22\%) followed by septicaemia $(20 \%)$, viral fever other than dengue $(15 \%)$, dengue $(12 \%)$, enteric fever and pyrexia of unknown origin $9 \%$ each. Other conditions were acute febrile illness, alcoholic liver disease and unknown bite.

Gandhi AA et al (2015) ${ }^{[11]}$ study found malaria to be most common cause (41\%). Dengue was the second most common cause $(26.8 \%)$.

In Nair study (2003),[12] septicaemia was the leading cause of fever with thrombocytopenia. Second common cause was enteric fever followed by dengue, megaloblastic anaemia, malaria and haematological malignancy.

These differences in various studies might be due to different geographical areas and local conditions, which may influence disease outcome.

Majority $(95.6 \%)$ of the cases in the present study showed good recovery, which was similar to findings by Sujata S. Kumbhar et al (2017) ${ }^{[8]}$ where $82 \%$ cases showed good recovery and mortality was $8 \%$.

\section{CONCLUSION}

Febrile thrombocytopenia is an important clinical condition commonly caused by infections: dengue, malaria, unknown viral fevers and septicaemia. Febrile illness patients should be investigated for low platelet count, whether they have bleeding manifestations or not. A routine CBC (Complete Blood Count) investigation in all febrile illness cases will help to find its association with thrombocytopenia, which will narrow the differential diagnosis of fever.

\section{REFERENCES}

[1] Konkle BA. Disorders of platelets and vessel wall. In: Fauci AS, Braunwald E, Kasper DL, et al. eds. Harrison's principles of internal medicine. Vol. 1. 17th edn. New York: McGraw-Hill 2008: p. 718-23.

[2] Craig JIO, McClelland DBL, Watson HG. Thrombocytopenia. In: College NR, Walker BR, Ralston SH. eds. Davidson's Principles and practice of medicine. 21st edn. Edinburgh: Churchill Livingstone/ Elsevier 2010: p. 1003-4.

[3] Abrahamsen SK, Haugen CN, Rupali P, et al. Fever in the tropics: aetiology and case-fatality - a prospective observational study in a tertiary care hospital in South India. BMC Infect Dis 2013;13:355.

[4] Parikh F. Infections and Thrombocytopenia. J of The Association of Physicians of India 2016;64(2):11-2. 
[5] Singhi S, Chaudhary D, Varghese GM, et al. Tropical fevers: management guidelines. Indian J of Critical Care Medicine 2014;18(2):62-9.

[6] Bhalla A, John M. Syndromic approach to tropical infections. Update on tropical fever. The Association of Physicians of India. http://www.apiindia.org/pdf/monograph_2015_upda te_on_tropical_fever/002_syndromic_approach.pdf (last accessed on 1st June 2018).

[7] Gondhali MP, Vethekar M, Bhangale D, et al. Clinical assessment of fever with thrombocytopenia - a prospective study. Int J Med Res \& Health Sci 2016;5(1):258-77.

[8] Kumbhar SS, Kanetkar SR, Mane AM, et al. A Study of clinical and laboratory profile of patients having fever with thrombocytopenia and its outcome. Indian Journal of Basic and Applied Medical Research 2017;6(2):282-9.
[9] Meena R, Meena NK. Clinical profile of fever with thrombocytopenia in tertiary hospital, Jhalawar Medical College. JMSCR 2016;4(12):14535-9.

[10] Anand N, Talib SH, Bhushan A, et al. Clinical outcomes of patients presenting as fever with thrombocytopenia in Marathwada region. International Journal of Science and Research 2016;5(2):530-3.

[11] Gandhi AA, Akholkar PJ. Clinical and laboratory evaluation of patients with febrile thrombocytopenia. NJMR 2015;5(1):43-6.

[12] Nair PS, Jain A, Khanduri U, et al. A study of fever associated with thrombocytopenia. JAPI 2003;51: 1173. 